\title{
"Speculative Entropy: Dynamism, Hyperchaos and the Fourth Dimension in Environmental Law Practice"
}

\section{Lucy Finchett-Maddock}

\section{Handbook of Research Methods in Environmental Law, Edward Elgar Publishing Handbooks of Research Methods in Law Series}

This chapter seeks to approach environmental law education through a 'speculative' methodology of entropy in environmental law practice. It is suggested that entropy as the basis of a theory of 'complexity', and its usefulness in terms of understanding systems of law, ecosystems and the human and non-human relationships between them at the same time, is helpful when considering the protection of the environment and how we may teach the law that regulates this, and discover it in educational and daily practice. Complexity accounts for both micro and macro behavior and how agents and systems interact and integrate with their environment, and thus it is argued as an appropriate framework in the study of environmental law, accounting for not just individual rights and the actions of states or corporations, common rights and the rights of non-human entities and the environment over all, but also relations between these and even rights that we do not yet know nor understand. This is why the complex-adaptive processes of entropy are speculative as they take in to account the dynamism and preponderance of chaos, uncertainty and the unknown within and outside law and the environment and our multi-faceted relationships within its matrix, highlighting the enigmatic and becoming nature of the external world, our relation to it and the law that governs it. A speculative understanding of entropy also confers both understandings of linear and nonlinear time, where complex thermodynamics not only attests to time existing chronologically, but in other formulations that we may not even have the words as yet to describe.

Why is this useful to the practical understanding of environmental law? How are we to know how to govern ourselves in relation to the world or even envision new and unknown understandings of rights and law if we do not yet know if there is an alternate reality beyond what we have constructed for ourselves?

This chapter suggests this entropic methodology can be used in the exercise of exploring other possibilities for the teaching law through environmental clinical legal education, in the aim of teaching and learning a speculative environmental law practice. It is argued that speculative entropy is an openness to the existence of alternate variants of combined time and space (space-time or nonlinear time) allowing for new epistemological configurations of law and the environment around us, where humans, laws, animals, atoms, are all subject to the whim of contingency and necessity in the creation of matter. Speculative entropy places alternate conceptions of the 'fourth dimension' at the heart of environmental law education allowing the dynamic, chaotic, unknowable and unfathomable nature of law and nature to be taught as an ontological tool both within and outside the classroom.

Complex dynamic behaviour makes way for nonlinear time as well as linear, and through acknowledging this we can speculate how emergent and becoming conceptions of time can be made 'real' through the necessity of contingency (and the contingency of necessity) and begin to foresee the possibilities of new ways of learning law and environment, and interacting with the world we have around us, through the underpinning role of time.

Inspiring Guattari-infused 'ecosophical' project 'Skill City' run by Henk Oosterling and Aetzel Griffieon in South Rotterdam, Netherlands, is presented as a magical case study expressing a 
philosophy sympathetic to a speculative entropy, as well as the 'lawscaping' pedagogy of Andreas Phillippopoulos-Mihalopoulos' 'Walking the Lawscape'.

\section{Introduction}

"The duty of philosophy should be to intervene here actively, to examine the living without any reservation as to practical utility [...] Its own special object is to speculate, that is to say, to see".

Henri Bergson (2014 [1907])

Epistemologically, the processes and product of entropy, following the work of J. B. Ruhl, Paul Cilliers, Boaventura de Sousa Santos, as well as more recently that of Jamie Murray, Julian Webb and Thomas Webb, offer us a way of envisioning law and systems that does not strive for a totalising methodology, but one useful and poignantly characteristic of the limits and delimits of law. The capaciousness of entropy demonstrates the performance and matter of law through describing relations and structures that are ongoing and ever-changing, whilst at the same time being methodologically useful with practical impetus in the real world, leave from dense theoretical text through the viability of new pedagogical designs.

Accounting for the both predictable and unpredictable nature of entropy is similar to speculative realist explanations of materialisms which confer the 'becoming' nature of the natural and social world, to the extent that matter is brought in to being through processes of contingency and necessity, which are either based upon, or reminiscent of, the science of thermodynamics underlying complexity and entropy. This emergent nature relies on the preponderance of uncertainty which from a speculative perspective means there is not just one, total way of being, but that there are many. It is an acceptance and exploration of the possibilities of there being infinite ways of organising, teaching, learning, lawyering and living in tandem with the environment and ecosystems around us, that we are yet to fully comprehend.

The work of speculative realist Meillassoux will be used specifically (as opposed to others working in new materialisms such as Martin Hägglund who is critical of Meillassoux's understanding of time and contingency) as he relays the 'hyperchaos' of time whereby its becoming, emergent determination can mean contingency is infinite and can move in any way - practically anything is possible, including new temporal and legal formations, to the extent that the only absolute is the very fact that this is the case.

Dynamic systems governed by the laws of thermodynamics, confer the monopoly of time going in a linear direction, as the more complex a system becomes, the more disorder it creates, and this gathering of disorder (entropy) is understood to always increase, and not decrease, which accounts for aging processes, deterioration, degradation. At the same time, theories of complexity based upon entropic processes also relay the emergent and unpredictable nature of all systems, to the extent that there is never one system the same, never one trajectory repeating the exact movements of another, thus allowing for the preponderance and possibility of entropy moving in a different direction, i.e. that it may not gather, but reduce. Manuel de Landa confers the multivariant and unpredictable nature of systems by stating that "... rather than being a unique opposite, nonlinear patterns represent a variety of possibilities of which the linear case is but a limiting case" (de Landa, 2009: 382). A divergence in entropy could happen, the possibility is there, thus meaning that systems can happen backwards, sideways, in ways in which we can only speculate.

What a speculative understanding of entropy may account for, is how the environment around us infects law and how law infects the environment, and this is what in entropic terms would be considered the 'negative' entropy upon which a system relies to keep going, the energy that it takes 
from its surrounding in order to remain functional as a system at all. Negative entropy is a scientific conception of potentiality, becoming, the Derridean l'avenir or the trace, the hidden fuel for emergence through which systems evolve in both linear and nonlinear formations. Negative entropy is what de Landa may describe as 'possibility space': "... It follows from this that explaining a given emergent effect involves describing not only a concrete mechanism but also the singularities structuring the possibility space behind the stabilizing tendencies manifested in those mechanisms emergence and potentiality" (de Landa 2009: 389).

What we shall see over the coming pages is the import that a speculative understanding of entropy can have to not just environmental law scholarship, but also that of environmental law pedagogy in the form of clinical legal projects where students are working with the substance of the interjection of law in the environment and vice versa, through practical engagements using speculative entropic frameworks.

Entropy is not only a by-product of a system's complexity but has further, foundational epistemological impact than that, and to the radical role of speculative entropy in arguably all areas of both animate and inanimate life we turn to now.

\section{Understanding Entropy}

So what is speculative entropy? You are probably wondering what entropy is, let alone a speculative version of it, so first to an explanation of entropy (speculative or otherwise).

Entropy is, amongst many other definitions, a scientific explanation of the relationship between order and chaos within dynamic systems, purporting a linear trajectory of the arrow of time where the more complex we become the more dissipative and disordered we move simultaneously, a process occurs that is predominantly uni-directional, exemplified and defined by aging itself. Whilst at the same time not discounting the possibilities of nonlinear temporal modes the method of measurement at the simultaneously being the amount of usable energy within a system. The more complex a system becomes, the more energy it uses. Paradoxically, thus the more it strives towards order, the more disordered it becomes. Entropy is thus a quantitative measure of the amount of disorder in a system (Arnheim, 1971: 8). The more entropy there is, the more there is chaos. This is the Second Law of Thermodynamics, that energy, although constant in amount, is subject to degradation and dissipation (Arnheim, 1971: 9), and thus systems strive for order but move towards maximum disorder. This conflicts with the First Law of Thermodynamics, that energy may change from one system to another but is neither created nor destroyed.

Entropy is referred to in mathematics and biology in a myriad of terms, most notably within thermodynamics, complexity science or chaos theory, and can be divided in three broad contexts: information or complexity, the arrow of time, and uncertainty. The more information there is in a system, the more entropy there is, the more complex it becomes, the emergent properties of the system accumulating to create phases that are greater than the sum of their parts, whilst entropy functioning as the necessary exhaust. The entropy that occurs as a result can only ever be supplemented to and not be reduced, thus giving scientists good reason to confirm that time can only ever go in one direction. There is the slightest of possibilities, however, that as a result of the emergent movement and interfacing of each new part of a burgeoning system, that time could be reversed, thus allowing for the chaotic movement of entropy production - uncertainty, a chance for nonlinear time. For example, it is far less likely, in fact almost infinitely unlikely that a cliff should turn the powers of erosion on its head, and gather boulders and rocks from the sea to re-touch its coastline silhouette. It is highly probable that erosion will cause a cliff to lose its order through the interaction with the order of the elements, forcing materials and rocks to fall and diminish the cliff. 
But at the same time there still exists that possibility of time moving in nonlinear directions in the face of the preponderance of irreversibility in time.

What makes there a past and a present in systems is a nod to randomness and uncertainty, which is more accurately described as 'negative entropy'. If entropy is the amount of energy a system has used, then negative entropy is the amount of energy or 'orderliness' that a system 'sucks' from its environment to ensure a balance between order and disorder and that the system does not tip into total chaos, annihilating itself. Negative or 'negentropy' as termed by Léon Brillouin (1953: 11531163 ) is described by scientist Schrödinger as ".. the essential thing in metabolism is that the organism succeeds in freeing itself from all the entropy it cannot help producing while alive" (Schrödinger, 1944: 67-75). Thus negative entropy is ".. itself a measure of order" (1944: 67-75). The character of negative entropy alters dependent on whether it is a closed or open system, arguably there being infinite possibilities of alteration as a result of environmental conditions occurring in an open system. This question of what is an open or a closed system is central to an understanding of both emergence and materialism, being the concern of both schools of thought for dynamic processes within not just open, animate or 'alive' objects but those so too that are supposedly closed and inert.

As just mentioned, entropy is of consequence in our understandings of time, our concern for predictability and unpredictability, as well as how ordered and disordered a system becomes. This order is better known as complexity and now has forbearance in not just the sciences but now also the non-natural sciences. Complexity theory, evolving out of the mathematic and physical sciences, highlights the connection between the dynamics and processes occurring in material and biological life with that of social life (Escobar 2003, 349). Complexity theory itself is defined by Byrne (2005: 97) as, "the interdisciplinary understanding of reality as composed of complex open systems" and as described by Kavalski (2007: 5) as referenced by Edelman (2012), these systems are so complex that they determine a "the multitude of their components, the many feedback loops (...) and the numerous interconnections".

Theories relating to this are all based on various understandings of entropy. According to the Cilliers (2001: 5), complexity science can be categorised into three general forms, the first being 'reductionist complexity' whereby:

"Premise 1: There are simple sets of mathematical rules that when followed by a computer give rise to extremely complicated patterns. Premise 2: The world also contains many extremely complicated patterns. Conclusion: Simple rules underlie many extremely complicated phenomena in the world, and with the help of powerful computers, scientists can root those rules out".

The second type of complexity science refers to the 'soft' variety whereby complexity thought can be used as a powerful lens through which organisations can be understood (Cilliers, 2001: 6). The third is furthered into abstraction and questions the "epistemological consequences of assuming the ubiquity of complexity" (Cilliers, 2001: 7). Accordingly, under each of these three ever more abstracted brackets of complexity are genres which are (Cilliers, 2001: 8):

"descriptive, generative, computational, constitutional, taxonomical, organizational, hierarchical, operational, nomic, gnosiological, semiotic, semantic, algorithmic, informational, combinatorial, logical, functional, structural, entropic, cyclomatic, topologic, harmonic, syntactic, perceptional, and diagnostic".

Amongst other terminologies in complexity is 'emergence', the process through which entropy and negative entropy are created. De Landa, an emergence and assemblage theorist and famous for this 'A Thousand Years of Nonlinear History' (2000), relays in his piece in the collection edited by Levi 
Bryant, Nick Srnicek and Graham Harman (2011) 'The Speculative Turn: Continental Materialism and Realism', a definition of emergence, whereby if a ".. property of a whole is said to be emergent if it is produced by causal interactions among its component parts. Those interactions, in which the parts exercise their capacities to affect and be affected, constitute the mechanism of emergence behind the properties of the whole" (2011: 385). In essence, emergence is a non-reductive process where a whole does not equal the sum of its parts (Cudworth and Hobden, 2011: 37), as a result of the negative entropy sucked in and the positive entropy expelled and created, thus moving the system on in a cause and effect, linear and nonlinear dynamism. In the words of de Landa, "in other words, something is an emergent only to the extent that we cannot deduce it from a law, and it ceases to be so the moment a law becomes available" (2011: 382).

The mapping of movement from one cause to the next effect, an effect on to a cause, is the same as following motility from contingency to necessity, necessity to contingency. The necessity is metaphorically similar to negative entropy, that which feeds the direction and urgency of a system and allows it to develop from one stage to another, gathering a pocket of used energy as it shifts in pace, the positive entropy and its contingent results. The role of time in this, within CartesianNewtonian physics of time as absolute as an exemplifier, plots the bifurcatory points of a system from one stage to the next, along a linear trajectory. What more relative Einsteinian understandings of time relay is the not necessarily straight ahead determination of systems but that given the uncertainty of what might be within the negative entropy a system is about to use, systems become emergent in a nonlinear fashion too. As complexity theorist Edelman (2012) using John Urry (2006) explains:

"Causal effects are unpredictable and non-linear, time's arrow establishes bifurcation points that influence path-dependent evolution but do not determine it, the evolutionary process allows for emergent properties that cannot be fully reduced to its predecessors and physical, chemical, ecological or cosmic systems rarely tend to equilibrium."

So entropy is a (if not the) congenital part of complex, emergent processes, or 'complex adaptive behavior' as it is also described in biological mathematics and so otherworldly through the simple to complicated 'slime-mould' stories of Stephen Johnson's 'Emergence' (Johnson, 2001). A speculative version of entropy we will come to shortly, but how is any of this of use to understanding our relation between law and the environment?

\section{Using Entropy and Complexity in Law and the Environment}

How does entropy and its complex processes help us to understand our relation between law and the environment, the structures and developments in environmental law? First of all would be to consider how theories of complexity help us to understand not just natural systems but social systems and the links between the two. Secondly would be to understand how complexity theory allows us to understand the system of state law itself, whether ecologically focused or otherwise, with then a move to see how theories of entropy describe environmental law and the governance of legal relations within and between the natural world overall.

Theories of emergence and complexity which are based upon processes of entropy (and thus the underlying role of the fourth dimension - time and space) are to be found across the disciplines. The breaking down of disciplinary boundaries almost takes us back to eras of pre-niche knowledge where the discrepancy between the sciences of the natural and non-natural world are less clear and not as yet formulated as they are today. Aptly describe by Edelmann (2012):

"... the vanguards of complexity thinking are biologists applying second order cybernetics, meteorologists pioneering in computer simulation modelling and 
philosophizing physicians or physical chemists - not really the kind of innovators a discipline that only emerged in the late 19th Century as a knowledge system in its own right could easily embrace".

Such an adroit and adaptive theory and methodology obviously means that it will be adept in drawing comparators between apparently unrelated subjects and systems, such as law and the outside material world. Complexity theory not only describes processes within systems but also the fractures that create one system out of another, one epistemology to the next, whereby entropy accounts for the underlying dynamics of arguably all choreographies and vitalities in the life world. It is "... playing an increasingly significant role in understanding sociomaterial processes, too, because it appreciates their inextricability from a wider natural environment" (Edelmann, 2012), and thus its usefulness for describing ecosystems other natural phenomena that are all governed by uncertainty, temporal and spatial movements and shifts in order and disorder, is unique. Of course, coming out of the natural sciences, complexity theory is automatically akin to describing the natural world, species, habitats, biological structures and coordinates, but it is also unparalleled in its ability to relay the effects of human action (and inaction) upon the outside world; the cause and effect of our behaviours on all other systems, our social system of law and governance being just one of our many permutations.

So what has complexity theory told us as about law so far and how is it being used by legal scholars? Murray's 'Complexity Theory \& Socio-Legal Studies' (2008: 238), drew upon the pioneering work of J.B. Ruhl to identify the introduction of the complexity theory framework into socio-legal studies, stating Ruhl as the first to work through the implications of complexity theory (or more precisely chaos theory) for the study of law (Ruhl, 1996a; 1996b; 1997). Milovanavic is also highlighted as one of the key mavericks of applying chaos theory to criminology and more specifically the sociology of law $(1992,1997)$. Murray relays Ruhl's considerable impetus to the study of law and complexity, and highlights how the element of uncertainty in complexity, the element of unpredictability and preponderance for entropy of baroque scales, describes law's 'emergence', as opposed to its much propounded reliability and supposedly foreseeable nature. This openness to systems of law being unfixed and becoming is a nod to entropy and its role in the process and as the product of law and its rules and procedures. Similarly, Hornstein (2005) highlighted the manner in which the movements of complex systems and their 'adaptive' capacities can be useful 'descriptive tools' with regards to constitutionalism and how U.S. public law is reminiscent of a complex adaptive system. Once again this speaks of a process not as yet complete, one that is by its nature unfixed and unbounded - constantly adapting given events, circumstances and environments - or at least its boundaries are unfixed. This is evocative of the systems theory based on Maturana and Varela's autopoeisis, whereby unity and distinction between the system and background being where the system and environment collide, denoting first order systems and second order systems with the alternating role of the boundary as central (Luhmann, 2012). Bibel (2004) further speaks of the need to embrace artificial intelligence (Al) in the production of law and how $\mathrm{Al}$ as seen through a complexity lens, can assist legal studies. The Luhmannian influence has similarly been expressed with new vigour and reaches through the works of Philippopoulos-Mihalopoulos, particularly in relation to law and ecology (2011).

More recently, the saliency of complexity theory has been re-asserted in a piece by Thomas Webb in 'Law and Critique' (2013), as an alternative to systems theory, and distinguished as quite separate from the work of Luhmann et al. by its becoming nature, its usefulness in describing the relations between law and its other, and yet setting it apart from systems theory as a body of understanding which is not closed, reliant on adaptation and a constant re-drawing, reconfiguration of boundaries (2013). According to Julian Webb (Webb, 2005: 227): 
"At the root of the critical concern lies a deepening understanding of law's capacity to resist and absorb resistance, while at the same time expanding to juridify an everbroadening range of social relations ... [By understanding law as a] complex system, we can create new strategies for the normative reconstruction of law."

Webb has argued that complexity theory offers boundaries as contingent, emergent interfaces allowing for new ways to assess legal structures. This would agree with Murray (2008) whereby a complexity theory of law allows for the search for lost, hidden, local, bottom-up, emergent modes of legality, and for a new conceptual creativity in [legal] work (Murray, 2008: 227). This emergent understanding of law describes not just state law processes but also those of non-state laws and non-legal movements, and has been used extensively in the legal pluralism of sociologist and economist Boaventura de Sousa Santos (1995; 1999; 2001; 2003; 2005). Akin to the work of Arturo Escobar (2003; 2004; 2005), Santos crossed the disciplinary boundaries of science, law and that of the social sciences through a social movement understanding of emergence, i.e. complexity which is the way in which disciplines tend to recognise entropy, although perhaps not referring directly back to entropy itself. From varied fields of inspiration, this has been applied through a distinctly radical use of the bio-mathematical study of self-organising behaviour, alongside Marxist philosopher Ernst Bloch's conceptions of the 'Not and the Not Yet' (Bloch, 1995). He puts forward the sociology of absences and the sociology of emergence as the means through which, "...social experience that resists destruction is unconcealed, and the space-time capable of identifying and rendering credible new counter-hegemonic social experiences" (2003: 238).

This echoes the application of the mathematic and physical science-disciplined complexity theory, by Escobar. Escobar treats categories of self-organisation, non-linearity, and non-hierarchy as those that are not peculiarly the products of biology, but can also be applied to the observance of social movement behaviour, law, and social life in general. Undoubtedly, this is also conspicuously found in the work of Deleuze and Guattari (2004), Latour (2007), de Landa (2001) and Johnson (2001), with regard to cyberspace, urban studies and of course, assemblage and actor/network theory. Emergence, similar to the 'emergent law' that Murray describes (2008), can be determined as bottom-up behaviour, "... when the actions of multiple agents interacting dynamically and following local rules rather than top-down commands result in some kind of visible macro-behaviour or structure" (Escobar, 2003: 251). Escobar applies this in relation to an analogy of the swarm, whereby sea-life amass to create a greater shape in order to protect themselves. Apply this to law, whether state or otherwise, and a useful understanding of the bottom-up behaviour of social actors and the processes and product of entropy is made available. Santos' and Escobar's work is automatically of great compliment to the gathering work on law and complexity, serving as a reminder that law acts in a becoming, 'Not-Yet' state, the l'avenir of entropy itself.

This becoming narrative in entropy processes describes ecosystems directly, and as we have seen can account for agential to collective behavior, whether in the form of state law, opposition to state law or another form of alternative plural legal sanctioning and normativity that lives outside of the state. The fact that horizontal, emergent and leaderless practices, can be used to describe juridical and legislative structures, has always been of fascination for me, given the anarchist tendencies of bottom up and chaotic behaviour over that of top down orderly movements. Entropy, emergence and complexity relay human and non-human relationships with equal competence, and so this is helpful when considering the protection of the environment and how we may teach the law that regulates this, and discover it in educational and daily practice. The connections that can be made between ecosystems and legal systems, in both a substantive nature (through the gathering of matter as flora and fauna in a nature-based system or a statute book in law, as all necessitating entropy exerted) and also procedural (the accounting for uncertainty and the dynamic within the creation of entropy, the ingestion of the fluctuations of a surrounding environment such as weather 
conditions in ecosystems, or the effects of political events in constitutionalising law - you could even swap the effects of politics and law on ecosystems to weather on political events in a similar cause and effect entropic manner). This is the perception that "everything is connected to everything else" that complexity relays so well, to the point where our ".. essential (and strict) bifurcation into the human and the non-human makes little or no sense" (Edelmann, 2012: 6). Indeed, "Ecosystems and human social systems are all complex systems in their own right .. with distinct features ultimately they are co-constitutive, overlapping and intersected" (Cudwortth and Hobden, 2011: 49).

Of course, if you are talking of law in terms of complex adaptive behavior then you are relaying the underlying role of positive and negative entropy which in turn signals a temporal and spatial theory of law, an acceptance of the fourth dimension as the governor of law, where linear or nonlinear epistemologies of time give way to linear or nonlinear versions of law. It is to this structurating function of chaos and the fourth dimension in law and the environment that we will turn to next as a cardinal catalyst of not just entropic theories of complexity, but so too the philosophical rabbit-hole of speculative reason.

\section{Getting Out-of-Self: Enter Speculative Reason}

So how can we now understand the exegeses of entropy in terms of a speculative realist account and why is it important that we link the two in the first place?

It can be confidently predicated that all speculative theories are one way or another based upon the duration and flow of time, which logically asserts that they are similarly all based on an understanding of entropy, of both the negative and positive variety. Thus a turn to speculative realism is really a turn to philosophical reflections on entropic processes, the very becoming of matter through contingency and necessity. Speculative realism arrived as a radical philosophical movement, influenced by post-humanist, post-critical theory, known as the 'critique of critique' whereby the anthropocentricism of broad swathes of preceding philosophical engagement is challenged by a turn to a realism outside of our conceptions, which is similarly altered from the realism of pre-structural and post-structural thought. According to Bryant, Srnicek and Harman (2011: 2) in the introduction to their edited collection on the 'speculative turn' in philosophical thought, pre-speculative reasoning gives us ".. less a critique of humanity's place in the world, than a less sweeping critique of the self-enclosed Cartesian subject. Humanity remains at the centre of these works, and reality appears in philosophy only as the correlate of human thought".

This turn away from a humanism concerned for its subject only, has origins in the post-humanism of Heidegger's nonduality (Rae, 2004), Derrida's 'trace' and the deconstruction of différance (Castree and Nash, 2004). According to Castree and Nash, Derrida and Agamben both highlight the division of the human from the 'animal' feeds into the workings of the 'anthropocentric machine' whereby humanity defines itself through its différance and simultaneously operates through that which it sees itself separate from, that which is exterior to its regime of truth through which its own quiddity is substantiated (Agamben 2004: 37 quoted in Castree and Nash, 2004: 1353):

"Insofar as the production of man through the opposition man/animal, human/inhuman, is at stake here, the machine necessarily functions by means of an exclusion (which is also always already a capturing) and an inclusion (which is also always already an exclusion). Indeed, precisely because the human is already presupposed every time, the machine actually produces a kind of state of exception, a zone of indeterminacy in which the outside is nothing but the exclusion of an inside and the inside is in turn only the inclusion of an outside". 
It is through the works of Spinoza, Bergson, Deleuze, Serres, Latour, Haraway that the turn to understanding humans as human 'bodies', as "..always already an effect of their composition in and through their relations with the World" where the human has always been a small actor in the greater ceaseless and ongoing ontological movements of life and matter (Castree and Nash, 2004: 1354). According to Elichirigoity thinkers such as Latour and Haraway ".. invite us to think about technology as co-emergent with social and natural worlds, and not as something alien to them" $(2004,1357)$, a concern for social and natural correlates which is similarly found in the science and theory of complexity and entropy, and processes of which Latour is a specifically a cogent exponent of. It is through understanding the peripheral placement of the human in everything that Feenberg (2000: 153) sees as an opportunity to discern the 'assemblant' nature of human involvement in the world around us, where "... the contingency of the social can be distinguished from the necessity of the natural" (Feenberg quoted in Castree and Nash, 2004: 1357). In more recent perturbations of post-humanism there has evolved a 'dark ecology' by writers such as Timothy Morton whereby the idea of nature is dismissed as an anthropocentric fantasy that condescends the true power of its forces and our utter impotence over the 'natural world'. Aretoulakis describes this as a critique which ".. would entail ceasing to think about nature completely: not only with the purpose of exploiting it but also of admiring it (!)" (Aretoulakis, 2004: 175). Indeed as Dark Ecology art project propounds on its website (http://www.darkecology.net/about):

"Ecology does not privilege the human, it is not something beautiful, and it has no real use for the old concept of Nature. What we now know about the impact of human beings on the planet has led to the need to rethink the concepts of nature and ecology, and exactly how humans are connected to the world. This rethinking occurs in philosophy as well as in the arts."

What the shift away from the import of hominid placement within surrounding physical and nonphysical systems brings forth is an awareness of the reality surrounding us, and that which not all speculative theorists are entirely in agreement upon, is an acknowledgement of realism which challenges the Kantian tradition of mind and body correlation where there is no world outside of our own perception. This is what speculative realist Quentin Meillassoux terms as 'correlationism', the "idea according to which we only ever have access to the correlation between thinking and being, and never to either term considered apart from the other" (Meillassoux in Bryant et al. 2011: 3). This correlationism is strong in poststructuralism whereby there is no such thing as that which exists without a performance of the senses, there is no 'noumenan', objects and processes external to our perception. Thus speculative realism moves towards a 'materialism' that understands, in Žižekian terms, the reality we see is never 'whole' which he argues is not because there are parts that elude us but because there is a space we cannot see, a zone which is ourselves (2006). The works of Badiou, Deleuze and Althusser similarly relate historical through to mathematical materialist accounts of speculative reason (Ó Maoilearca, 2014: 13). Indeed according to Bryant et al., "one of the key features of the Speculative Turn is precisely that the move toward realism is not a move toward the stuffy limitations of common sense, but quite often a turn toward the downright bizarre" (2011: 7). Referring to an outside is even clear within the recent 'Accelerationist' movement, relaying the metabolism and energy of neoliberalism, albeit not always strictly as critique (Srnicek and Williams, 2014):

"Accelerationism pushes towards a future that is more modern, an alternative modernity that neoliberalism is inherently unable to generate. ... The future must be cracked open once again, unfastening our horizons towards the universal possibilities of the Outside".

So to see a reality beyond our senses is not to return to pre-critical thought, to the exact Cartesian dogma of duality, but to recognise that our realities are our own, that there are realities of the other, there are realities between ourselves and the other - and that there are realities that we are 
yet to know. This would agree with a Latourian notion 'irreductionism' whereby all entities exist equally to the extent they all interact or have the potency to interact and influence one another, with varying degrees of ascendancy (Bryant et al., 2011: 6). These realities are materialisms, the noncorporeal that can ascertain vitalities in themselves, accentuated through the development of 'Object-Oriented Ontology' (OOO) and 'Object-Oriented Philosophy' (OOP). This willingness to step 'outside of self' is the core of speculative thought, with a poignant reminder from Bergson (2014 [1907]) that: "The duty of philosophy should be to intervene here actively, to examine the living without any reservation as to practical utility [...] Its own special object is to speculate, that is to say, to see".

So OOO, OOP and speculative reason all seek to decentre the human and account for the vitality of matter in itself, conjecture which relies on the resonance and dynamism of positive and negative entropy, the becoming and emergent formation of both closed and open systems. The question is, and one that underpins the concerns of speculative reason and similarly this piece on environmental law and practice, is to what extent can we consider a system to be dynamic? I argue that a speculative understanding of entropy allows for the existence of negentropy whether a system is deemed closed as opposed to open, thus all systems in one form or another are open from the very start. These closed systems could be rocks, mountains, tables, buildings, material objects which are considered to be devoid of vitality, unless you pose the proposition that negative entropy enters all systems, meaning everything conjures a dynamism, even rocks, mountains, furniture, so they are always in a state of becoming, just at altered temporal rates. Then the question which brings us straight to the work of Meillassoux, is where did the first negentropy come from? What creates matter from the void, was there a void, and how is this contingent or necessary? Put surreally by Ramey (2014: 33): "Given that this world is a world of contingency, the answer to the question "Why is there something rather than nothing?' can only be answered 'for no reason at all' ."

How does speculative reason inform entropy however, and vice versa? And of what use is this to environmental law practice and the methodologies used in Skill City and Walking the Lawscape? A comparison between speculative thought and entropy processes will follow, using the work of a range of theorists but also two central thinkers predominantly Quentin Meillassoux and Martin Hägglund, both of who are central to speculative thinking or at least the 'new materialisms'. It is through their work that a speculative understanding of entropy can be gauged in order to inform environmental practice such as the projects we will talk of shortly.

\section{Epistemological Junctures between Speculative Reason and Complexity}

By comparing the thoughts of speculative and complexity thinkers, it is hoped that the convergences and divergences between complexity and speculative reason can be brought to the fore. This is so that we can see how beneficial this mode of thinking, a methodology of mind and action, can be to environmental law pedagogy.

\section{i. Post-Correlationism, the Absolute and the Performative Contradiction of Getting Out of Self}

For Meillassoux, the task of speculative thinking is to remove itself from the shackles of Kantian performativity, and think in terms of the possibility that there exist relations which are our external to our understanding of them. Meillassoux claims that correlationism consists in disqualifying the claim that it is possible to consider the realms of subjectivity and objectivity independently of one another (2008: 13), and so the job of speculative thought is to acknowledge this correlative thinking as a reality in itself, but that are further phenomenon outside of this parallelist supposition. Meillassoux seeks to highlight the existence of something absolute beyond our consciousness through the de facto existence of 'arché-fossils', or events which happened prior to the arrival of human consciousness, such as the beginnings of life itself, and sees the Achilles heel of 
correlationism as its inability to cope with what he refers to as 'ancestral' statements (Hallward, 2011: 136). As Meillassoux so poignantly states for this exploration in new ways of thinking and teaching environmental law (2008: 8):

"The arché-fossil enjoins us to track thought by inviting us to discover the 'hidden passage' trodden by the latter in order to achieve what modern philosophy has been telling us for the past two centuries is impossibility itself: to get out of ourselves, to grasp the in-itself, to know what is whether we are or not".

There is a similar convergence in entropy processes whereby assuming that there are movements between metabolisms, whereby one system bifurcates into another which is the drawing of negentropy to expel the positive used vitality, is to allow the possibility that there are dynamic processes of becoming at play that are outside of the scope of human malleability. Similarly to Meillassoux, complexity theorists relay the existence of formations that are neither predictable nor unpredictable, the only thing that can be confirmed is that random fluctuations will occur, which is according to Cilliers, an acceptance of an almost Habermasian 'performative contradiction' in complexity and entropy. This is whereby entropy looks like an absolute statement regarding the nature of systems, and yet within that statement it is propounding that there can never be a totalising law, it will always annihilate itself. As Cilliers admirably stated, "This view argues that complexity theory does not provide us with exact tools to solve our complex problems, but shows us (in a rigorous way) exactly why these problems are so difficult" (2005: 257-59). Similarly, what both speculative reason and complexity face are counterjections of biological reductionism, whereby entropy denotes systems which should be confined to the natural world, to biology and not psychological or social worlds, and absolutism can obviously lead to totalitarianism.

\section{ii. The Fourth Dimension}

As I predicated previously, all speculative theories are based upon the relation between entropy, both positive and negative, as they relay our position in time and space, and in a sense, all theories and all thinking about anything, are similarly placed in such coordinates. What both speculative reason and entropic movements show, is that all our thinking and actions take place within a ripple of the fourth dimension, according to Meillassoux the challenge therefore being "...to understand how science can think a world wherein spatio-temporal givenness itself came into being within a time and a space which preceded every variety of givenness" (2008: 41).

What I find so important to this exploration into the surrealisms of speculative reason, is the fact that not only can it account for one version of time, but it may account for many, and it is a debate between thinkers on the malleability if time itself Meillassoux and Hägglund that underlines the opportunities speculative thought gives us to understanding the world around us and the law that governs our interaction with it.

Meillassoux's philosophy of time is based upon his acknowledgement of there being an external reality, a realism which has happened prior to human explanation and thus is governed beyond us. This beyond, or absolute, is the power of time itself which has the capability to destroy as much as it does to create (2008: 62): 'it is absolutely necessary that every entity might not exist ... the absolute is the absolute impossibility of a necessary being". He returns us to the very enquiry of not just legal philosophy, the search for the origin, but to thought and epistemology as a whole, whereby he states that "... time without development [devenir]" has the "... potential to generate life ex nihilo, to draw spirit from matter or creativity from stasis-or even to resurrect an immortal mind from a lifeless body" (Hallward, 2011: 133).

This is radical thought and one that is bound to attract opposition but at the same time is refreshing to the extent that it acknowledges time can move in an infinite number of mysterious ways. The role of entropy here is fundamental and questions where negative entropy at the very start of life, 
must have come from. Can it be that all life already invests within itself the poeisis available to it to become other than to itself? In a sense is there ever a moment whereby there is no negentropy and life begins ex nihilo? Meillassoux believes that this is so, and the reason for this is contingency itself, there is no necessity for its creation (2008: 53):

"There is no reason for anything to be or to remain thus and so rather than otherwise [...]. Everything could actually collapse: from trees to stars, from stars to laws, from physical laws to logical laws; and this not by virtue of some superior law whereby everything is destined to perish, but by virtue of the absence of any superior law capable of preserving anything, no matter what, from perishing".

This absence of law as the creator of all laws is reminiscent of the entropic performative contradiction, whereby in order to proclaim the world is valueless, one makes a value-laden statement to ground the same. By asserting that at any given moment of order there can be disorder, is to assert the 'virtual power of contingency', a deviation of negentropy reverting itself and becoming entropy per se. Meillassoux even attests the possibility of God, not in the sense that he may currently exist but that thought the swerve of clinamen, it is not impossible that she or he can come into matter in some form or another in the future at same time.

Hägglund disagrees with this stating there can be no "... contingency without the succession of time, which entails irreversible destruction and rules out the possibility of resurrection a priori" (2011: 116). This relies upon the creation of positive entropy, the purported arrow of time, which is one and the same as Meillassoux's reliance on a temporal absolute once again. From Hägglund's point of view, there is no 'flow' of time outside of spatialisation, a process which he refers to as arché-materiality, Kantian succession, "since time has to be spatialized in order to flow in the first place. Thus, everything we say about time (that it is passing', 'flowing', 'in motion' and so on is a spatial metaphor" (2011: 119). For Hägglund, time is irreversible (2011: 116) and must entail negative entropy in order for it to iterate itself; it is nothing but the negativity that is intrinsic to succession (2011: 121). He argues that if matter intrinsically houses negentropy then time itself can never move from one moment to the next, eliminating the possibility of succession where every moment must entirely negate itself or there would ".. be no time, only a presence forever remaining the same" (2011: 118).

What I argue is so refreshing about this debate, and particularly the possibilities held within Meillassoux's conception of nonlinear time, is that if is enough to believe Hägglund if we are to stick to the laws of physics with which we have become familiar, and always attest to the linearity of time, then we are ignoring the possibility that all laws are capable of breaking down at the rupture of uncertainty and contingency of which Meillassoux so clearly regards as the absolute, the perturbation in itself of the event horizon.

\section{iii. Dynamism, Becoming and Negentropy}

It is this congenital link of uncertainty and chaos between entropy processes and speculative thought, particularly that of Meillassoux, that brings together the two intertwined epistemologies. Meillassoux derives the necessity of contingency as 'hyperchaos': the result being that anything is possible from one moment to the next. This gives us an indication of the kind of reality with which we are dealing when referring to the thought of Meillassoux, whereby according to Hallward it is a realism that ".. does not involve the way things are so much as the possibility that they might always be otherwise" (2011: 131).

This philosophy of immanence, a form of Platonic 'hylozoism' whereby everything contains within it a vitality of all matter in some form or another, from spirit to rock formations, to seas, to electronics, 
to humans, to theories of speculative entropy, exceeds the rational comprehension of natural processes (Meillassoux, 2008: 121). If the critical question that appears here is 'Why?' then I say the answer might be a grand 'Why not?'. Indeed as Ramey (2014: 33) puts it: "Given that this world is a world of contingency, the answer to the question 'Why is there something rather than nothing?' can only be answered 'for no reason at all'".

Sound familiar? Chaos is the basis of emergent, complex and entropic processes - the power laws, the preponderance of uncertainty and the ever present balance between positive and negative entropy. Cilliers brings together post-structuralist accounts of philosophy with that of entropy and complexity and seeks in his writings up until his untimely death in 2011 , and highlights this becoming nature of entropy reliant upon the interjection of contingency and uncertainty. He speaks of Derrida's understanding of the 'impossibility of justice', whereby the 'incompleteness' of justice as a system is understood in a similar fashion to the way in which complex systems are seen to emerge and are always in a state of becoming (Cilliers, 2004: 19). This is in the same vein as Derrida who sees justice as incalculable, there can never be a fixed referent from one movement of ethics to the next, to ensure there is a just or unjust outcome due to the ever incompleteness of the past and future of the justice, never a totality. As in any structuralist or post-structuralist example of language use and meaning creation, both a complexity theorist and a Derridean (for example) would see language and meaning continually within a context, or in complexity terms, reliant upon its environment (hence entropy's complex-adaptive character). In a procedure similar to that of deconstruction, the product being at once the process, whereby the prescriptive is the descriptive and the same vice versa, emergence (creation of entropy) is the way in which a system is developing and adapting, dependent on the advent of uncertainty.

What complexity manages to do is account for the nature of law as a set of rules, and yet accepts that there is a need for a recognition of the need for an opaque level of reified positivity in their structure, and yet acknowledge that due to the very character of law, the dynamics of any system the existence of entropy itself - this assumption will break down, just like Meillassoux's absolute, the system relying upon the infinite changes that may happen to its surroundings to survive and therefore will adapt and emerge.

\section{From Critical to Speculative Entropic Environmental Law Education and Practice}

Of what use is any of this to an environmental law programme or the development of new tools for pedagogy? And how on earth does this work in practice?

First and foremost, the grounding philosophies of both entropy and speculative reason is to think beyond the political instantiations with which we have become familiar, and accept that there are primordial powers greater than the anthropocentric obsessions with war and capital than we are willing to admit. These powers are thus the stuff and matter with which environmental law concerns itself, the climate, ecosystems, the biosphere, species, glacial movement, ocean temperatures and our place within our solar system. At the same time, and with equal importance, what both entropy processes and speculative reason confers is that we are part of these movements at the same time, we are responsible for the overall trajectory of the planet, although we are not central to them. By thinking beyond the regime of individual liberal rights and more in terms of our part in processes of cause and effect, as one species amongst many, promotes the idea that there are other possibilities and alternatives to our political and social make up in connection with the natural world. This right-sizes us in developing laws that understand the power of the environment, our existence as animals as part of a greater network of other animals and beings, our responsible role in managing ourselves within this matrix, and how we relay these relations to our extant students. 
What have the thick questions around temporality to do with the teaching and practice of environmental law? By speculating, as Meillassoux does, that there may be other conceptions of time itself as a result of the movements of the form of time that we know, then he opens up the possibility of new ways of being and understanding in the world, a brave argument which exemplifies the fight against dogmatic thought of no alternatives, whilst at the same time understanding the degradation resulting from the arrow of time similarly. Hägglund's argument makes sense and is logical, but sensical and logical only to ourselves within our enclosed hominid framework and not truly expressive of a speculative thought that seeks to step outside of self and place humanist conceptions of the outside world as just one in a non-hierarchy of many. Speculative thought teaches us the positives of questioning the environments and laws around us, removing our ego from the potentials of our externalities and that entropy can go both ways, dependent upon the radical choice of uncertainty.

The element of becoming is the presence of negative entropy, of the preponderance of chance and unpredictability that this piece wishes to assert is positive in applying to a pedagogy of environmental law practice where the unpredictable nature of the environment can be acknowledged and ascertained within the classroom as well as the structure of the law that governs our relations and environmental rights. This uncertainty allows us to understand our inferior place in the world up against the determination of logic that may fall in on itself at the whim of climactic change, and yet at the same time allow us to be aware of our role in cause and effect as part of everything, as we always have been. Transdisciplinarian Cilliers would have said, rules, "... should be drawn up as if they were universally valid, but with the proviso that they have to be re-evaluated each time they are applied" (de Villiers and Cilliers, 2004: 48).

So how do we teach this as a new and improved environmental law pedagogy? By accounting for the non-human, the interspecies, the thermodynamic and the uncertain, we open the doors to new frameworks of reference beyond the individual and collective rights of humans, but to the rights of animals, atmospheres, trees (as famously wild lawyer Christopher Stone profoundly stated some years ago, 2010). What a speculative entropy of thought and practice in environmental law would seek to assert is an understanding of interspecies interconnection that no rights-based dogma can no longer describe sufficiently, or that indeed there may be rights regimes with which we are yet to be aware, always situating us as part of an assemblage, a constituent neither superior nor inferior in the law-environment matrix. Environmental education in recent years has sought to underline the 'lived reality of environmental crisis' through reinvigorating and re-educating both young and old on the non-human nature to which Houston describes as an 'ecological humanities' must respond (Houston, 2008: 179). Houston relays the importance of learning and observing the actions and organisational networks of social collectives and how they work to revitalize and remake their local and regional environments (2008: 180) and similarly Emmett relays the importance of community gardening in realising environmental pedagogy (2011).

Assemblant methodologies in environmental education have been suggested by Law (2004) through ontological and performative 'discovery and depiction of realities', through engagements with environmental projects to develop 'method-assemblages'. Houston (2008: 185) demonstrates the benefits from skills-learning in environmental education, whereby "Environmental knowledges that are performed through such active and collective engagements show us that it is also the everyday and ordinary stuff that matters because it generates its own kind of complexity". Specifically within the teaching of law, understanding us as part of an animal cartography whereby our sentience is not prioritised over any other creature, is the incorporation of animal welfare law into undergraduate law syllabuses, as discussed by de Almeida Silva regarding animal law education in Brazil (2014). 
With this in mind, I recently have had the pleasure to come in to contact with two projects that express the post-correlationist, ecological, temporally nonlinear and alternative conception of environmental education which I believe have the intrinsic tenets of speculative entropy at their heart, those being: Guattari-inspired 'ecosophical' project 'Skill City' of Henk Oosterling and Aetzel Griffieon in South Rotterdam, Netherlands; and the second example of speculative entropic practice in environmental law is the 'lawscaping' pedagogy of Andreas Phillippopoulos-Mihalopoulos' 'Walking the Lawscape'. First we shall turn to Skill City.

\section{i. Skill City}

Inspired by the 'ecosophy' of Felix Guattari's 'The Three Ecologies' (1989), philosopher and project executive Aetzel Griffioen describes Rotterdam's 'Skill City' as "an ecosophical traject from primary school to vocational education' with excluded neighbourhoods in the South of the city since 2007" (2015: 1). Designed within its mission statement, Skill City is a living and breathing example of a practical answer Guattari's (1995: 119-120) question on the micro level of the school class and the meso level of the school (Griffieon, 2015: 61):

"How do we reinvent social practices that would give back to humanity - if it ever had it - a sense of responsibility, not only for its own survival, but equally for the future of all life on the planet".

Rotterdam has become a city of elites but also the marginalized, with many immigrants and those unable to access mainstream education, rights and opportunities within Dutch society. Griffieon explains that it is the children and second generation of migrants who are bearing the brunt of exclusion whereby they are more prone to social and psychological depression and yet at the same time any resistance to discrimination and privileges afforded to non-migrants, is ".. in the guise of conservative and patriarchic values. These react to and feed back into the external forces of racist and extractionist bends that in turn also keep looping back" (Griffieon, 2015, 60).

Rather than a critical approach, Skill City asserts an 'ethological' spirit as essential (De Haan, 2014: 101 ) in countering these cycles, breaking the mould directly put into practice a form of ontological education where the dominant repressive ideology is challenged through hard and soft skills development and the nurturing of a new gentleness in those children facing marginalisation and exclusion. According to (DeHaan, 2014: 98), neighbourhood-revitalizing vakhuizen ('crafts houses') are being put in place under the banner of 'not chilling, but skilling.' By engendering practical methodology of environmental, social and psychological connection through the development of skills and attitudes that flourish the relations between each element, Skill City is responding to 'extractivism"s colonisation of each of these with a pragmatic resistance echoing a Guattarian concern to revive forms of solidarity through working "directly on the subjectivities of people inside and outside of the market-state" (Griffieon, 2015: 59). Following and directly applying the philosophy of Guattari, Skill City's belief is the only way to counter further enclosure, extractivism and neoliberal manoeuvres is through incorporating three ecologies into education starting at an early age, from the macro to the micro, 'where life first plays out' (Griffieon, 2015). These three ecologies are social ecology, mental ecology, and environmental ecology. This ecosophy is Guattarian, following the work of Gregory Bateson, and is an ecological approach to countering the biopoliticisation of all commons where to ".. halt the social and mental extinction of forms of solidarity, new commons must arise" (Griffieon, 2015).

So how does Skill City actually work? In order to replicate the values within ecosophical thought, the pedagogy relies on a drawing of relations between alternate 'planes of existence' through thinking 'transversally' (Griffieon, 2015: 60). This transversal education is put in to practice through the garnering of skills, manipulations of matter and thought of the mental, social and biophysical 
ecologies. Ecosophy is taught as a proper subject, and the children involved will be enrolled in the programme from early years to late teens to follow their development over time. Currently the project is focusing on the 'physical integrity' stage whereby according to Griffieon (2015: 61):

"Six to ten hours of the school week are dedicated to explicitly relational activities, organized in an ecosocial circle centring on the children's bodies. From the earth and back, the circle starts with eating together. Quite a number of parents, mostly mothers, middle and higher education interns and a professional cook prepare a two-course lunch every day: a warm meal and a bowl of fresh fruit afterwards. The pupils themselves are seated at long tables where the higher graders tend to the younger kids under the supervision of a parent or an intern".

Specific skills include cooking classes, gardening and permaculture through which growth, preparation and consumption of their own food is the first part of an 'ecosocial' circle (caring and regaining energy) and the second half concerns the expending of energy gained bodily and mentally in judo and philosophy Griffieon (2015: 61).

A truly radical project and one steeped in the same values with which this piece on speculative has been concerned all along. How does it link to a speculative understanding of the social and cultural matrix, time itself, and the becoming and incomplete character of entropy cycles through the presence of uncertainty?

Skills City, by its nature, is a nonhuman assemblage of ecological philosophy put into practice whereby according to DeHaan (2014: 99) it is so successful as an ecosophical project that it makes impossible to delink reliance on our modern 'bifurcation' of Nature and Society (or subject, culture, etc.):

"There are real, immanent flows of matter-energy-concrete, steel, biomass, skills, utterancesclaiming causality here, and they will not be reducible either to each other, 'natural context,' or 'symbolic constructions,' without completely distorting the efficacy of the assemblage as a truly heterogeneous whole".

This asssemblant nature of the project means that it is working as though a part amongst many, shifting and altering trajectories dependent on the stage the children get to in their lives, any specific troubles or difficulties with integrating they may be facing. The way in which Skill City works as is though a real time version of a Deleuze and Guattarian 'war machine', whereby explained by DeHaan (2014, 97): "...it functions as a kind of chaotic attractor, a strangely dynamic contraction of plans and projects ever evolving by drift, never returning to the initial conditions needed for a 'properly' linear quasi-experiment".

The way in which the nonlinear and emergent nature of the project develops is reflective of the way the children are interacting with their surrounding environment, the amount of negentropy they are imbibing, and the preponderance of chance and chaos. As a result, as the project shifts and changes according to the contingency and necessity of the events and interactions of and with the students, Skill City 're-territorialising' much like the war machine metaphor, in the school, the market, the neighbourhood and the city (DeHaan, 2014: 98). According to Griffieon in his reflections on the scheme's ecosophical drive, the epistemological and methodological basis of the programme is that there is a denial of totality, "... dealing with the excess of an infinity of possible threads of trace, weave and recount ... ecology becomes inclusive even for children, though at the price of also becoming infinite". This merging of the natural and the social in one of the most urbane of environs is achieved through the very recognition of nonlinearity and becoming, the nature of all systems whether traditionally seen as inert or otherwise, as in a constant state of balance between negative 
entropy and positive entropy, the denial of totality and a finite horizon of ecology being left behind through the fissure of chaos (Griffieon, 2015: 63).

Skill City is a project that is open and accepting of its dynamism, does nothing to try and reign this in, its methodology as reflecting the assemblage of the children within the Rotterdam city scape. By doing this, it fundamentally attests to a speculative assertion of the fourth dimension, the nonlinear movement of time as the pedagogy through which skills are being transversally taught across all disciplines, and altering dependent upon necessity, is the same as a Meillassouxian description of contingency and necessity. The project moves and shifts in a way which accounts for the possibility of anything happening throughout the course of the scheme, there is an acknowledgement of the presence of power laws which can shift the teaching and learning in multi variant patterns, not (or if so, very rarely) in linear formations. As a result, the project allows for a speculative understanding of entropy as it concerns itself with not only the arché-materiality of time but so too the command of hyperchaos of which Meillassoux tells us is what brings us to after finitude, to the dynamic and becoming nature of everything, to all systems as ecosystems whether based in the natural world or not, whether law or otherwise.

\section{ii. Walking the Lawscape}

Phillippopoulos-Mihalopoulos' 'walking the lawscape' is documented in his brave new work "Spatial Justice: Body, Lawscape, Atmosphere" (2015). Lawscaping is both a verb and a noun, naming and doing, which reminds us of the dynamic and open system character of all things and objects. Within Phillippopoulos-Mihalopoulos' work, we find a fundamentally object-oriented and speculative pedagogy that has been formulated specifically for students of his environmental law module at the University of Westminster, 'Law and the Built Environment'.

In his thesis of his most recent book, Phillippopoulos-Mihalopoulos asserts that there is no outside to the lawscape, but that it, and parts of ourselves, 'withdraw' in order to make way for the Other, this being the point at which spatial justice is possible. He claims that there cannot be two bodies in the same place at the same time, and thus in order for conflict to be avoided it must always involve a withdrawal of some form. This withdrawal occurs from human bodies, to apparently inanimate objects, which Phillippopoulos-Mihalopoulos would claim are not so, given his hylozoism and concern for the vitality and becoming of all matter. In this sense, there is never any escape from the lawscape, there is never a void or a moment of absolute radical contingency and chaos that inverts all other understandings of necessity and becoming. What Phillippopoulos-Mihalopoulos seeks to do with his students is to demonstrate the all-pervasiveness of law, the biopolitics that never appeared but was always not just a contingent pulsar from the beginnings of time, but that that it is everything and nothing synchronically. And this all omnipotence he sees as integrally spatial, there is no law outside of space and no space outside of law, thus there is only lawscape.

So 'walking the lawscape' is designed as a methodology that 'fleshes out' the materiality of the law being studied, to see the ways in which the bodies of the students 'lawscape' as a verb in the words of Phillippopoulos-Mihalopoulos, with the plan of the exercise is to discover if there is an outside to the lawscape (2015: 94). This thinking about the lawscape through the medium of the moving body he argues "brings forth the materiality of the law both in its spatiality and corporeality" (2015: 95), whereby the way in which law 'inhibits or encouraging certain senses' allows for a discovery of "..law as spatial, law as corporeal, material, spatiality mak[ing] law more or less visible" (2015: 94).

This is all methodologically guided by the students familiarising themselves with Deleuze and Guattari's 'A Thousand Plateaus' (2004) where they take the text with them while walking, tracing their movement on a map ".. if feasible and does not interfere with a spontaneous flow of movement"(2015: 95). Phillippopoulos-Mihalopoulos relates this to the 'diagrammatic reading' 
developed by Bottomley and Moore (2008), ".. revealing not the visible in the sense of the visual but the perceptive ... percepts work because they link together (carry through them) our ability (our need) to use sensor material as an aspect of thought" (Phillippopoulos-Mihalopoulos, 2015: 96)

Lawscaping reminds me of Bottomley and Lim's existential experience of 'taking 'the law' for a walk 'in land" (2009), the task of 're-embedding 'land law' into the 'everyday'. Through walking with law through the land, they argue there is a form of 'law in context' (2009: 1):

"Such a form of walking presumes a 'reality' to material conditions and pursues a form of legal critique which can do no more than require of law that it meets the needs exposed from an examination of that 'reality'".

The experience of law and walking is not to think of law and its authenticity as a dualism which assumes law is powerless without its supposedly a priori context, however (2009: 2). This reference to the physical experience of land and law as Bottomley and Lim's 'embodied geography' allows for both a corporeal placement within a cartography of geography, as well as the interpreted act of understanding law in the everyday. The composition and perspective of the actor, the performer, creates the law as they are walking, affecting "even from the practices of law itself, let alone its impacts on the messiness of 'everyday lives'” (Bottomley and Lim, 2009).

How does this remind us of a speculative entropy? Firstly, to expound that this is a methodology based on temporal considerations might not be quite what Phillippopoulos-Mihalopoulos had in mind, as his concern is predominantly with space and the second order nature of temporal duration within this. But what I would automatically purport is that in the same vein as Skill City, lawscaping seeks to reveal alternative and as yet unknown understandings of law and the environment around us, through revealing matter that is both visible and invisible. This is a speculative understanding of the law and environment interface and indeed a speculative account of environmental law teaching where new methods and previously untried practices reveal new ontological experience and exigencies for the students. As he explains, the radical pedagagy is speculative and ecosophical much like Skill City's ethos whereby human relations with the environment are re-thought and rediscovered at the important juncture of undergraduate higher education (2015: 94):

"The purpose of the walk is for the students to have an encounter with the lawscape and their own lawscaping practices, expanding their awareness of the way in which they employ their body, the law and space in the lawscape, so that they eventually manage to reorient the lawscape".

The very fact that the lawscape is based upon human contribution to the external and becoming assemblage of the environment, is a form of nonlinear and incomplete emergence which relies on negative and positive entropy, where the students are no longer experiencing themselves as selfcontained, fully determined human bodies, "but part of an assemblage, which however keeps on withdrawing" (2015: 97). This nod to nonlinearity, to the re- and de-tertitorialisation of the war machine, is a nod to the presence of Meillassouxian chaos, the whim of contingency.

\section{Entropy Methodology as Speculative Environmental Law Education and Practice}

What do both of these project teach us about what is needed for a speculative entropic understanding of environmental law practice? It has been clear for some time that we need to respect the character of the natural world around us and almost replicate its movements in law in order to be able to know our own place and respond appropriately in legislative and juridical forms. The accounting for human effects on the nonhuman world and the same vice versa is clearly of import to the discipline of environmental law, where we can begin to have a Copernican revolution around the non-anthropocentric placement of 
humanity within systems, and understand our connection to the all-encompassing ecosystem of 'the earth' (Cudworth and Hobden, 2011: 49). According to Dryzek, laws fail adequately to address environmental problems unless they embrace the complexity of the environment and the fact that environmental problems will never present themselves in 'well-defined boxes' (2012: 9-11); thus this foundational connection to the earth is that which places us amongst many other beings in the pecking order of the whims of the causes and effects of the climate. As Ko relates succinctly (2013: 25):

\begin{abstract}
"Environmental complexity arises from the natural interconnections within the biosphere, such as feedback loops and other causal pathways. Indeed, environmental physical constraints influence legal development; they may challenge the very legitimacy of environmental laws, even though the laws themselves are highly normative. This is a distinctive feature of environmental laws."
\end{abstract}

By allowing for the complex and becoming nature of the environment to be incorporated into the kind of polices and laws that are developed, from linear to nonlinear planning developments, to infrastructure projects that take in to account the causal effects of human activity on the local biosphere and the unforeseen and unpredictable effects that may ensue, Ko argues that "Complexity should enrich, rather than confuse, environmental understanding" (2012: 27).

Graham Harris has too put forward the case for an 'ecolophysics' in sustainability and environmental governance that accounts for the complex relations within systems, between systems and as a part of the knowledge systems that drive laws and legislative environmental protections (2007). Similarly, Farber (2006) relays how predicting for the unpredictable through generating models, understanding emergent and bifurcatory 'power laws', risks and interactions between systems can support the effectiveness of some of the foundational principles of environmental law such as the precautionary principle. It is through breaking down the distinctions between human and nonhuman complex adaptive behaviour and the uncertainty of temporal relations that derive from their positive and negative entropy production, that space can be made for "the invention of social mechanisms of coping aimed at reducing the otherwise unbearable degree of uncontrollability" (Nowotny, 2005: 20).

According to Whatmore we need an ontological relationality between 'being' and 'things' and how we can defragment the "performative entanglements between science, ethics, nature and culture" (Whatmore 2002 in Houston, 2008: 184). It can be argued that the strategies of both Skill City and walking the lawscape are both grounded in a core placement of practice, performance, enmeshed and experiential learning by doing. This skills-based teaching brings to the fore the brilliant benefit of clinical legal education as an obvious framework of pedagogy which can be manipulated to allow for new speculative entropic visions and innovations in environmental law teaching and learning. Similarly, as skills are taught transversally as part of Skill City, ecological concerns through ecosophical methods can be taught within each core law module and not just confined to and environmental law option.

The three tenets of speculative entropy are thus:

a. a speculative opening out of the mind to alternate conceptions of time which can give way to new forms of rights, new possibilities for environmental protection, discoveries of unknown laws of logic all based on the possibility of the inversion negentropy to entropy;

b. $\quad$ the immersion in the non-human assemblage through performance and practice of natural and social convergences in environmental law in order to understand the omnipotence of the fourth dimension in our every actions, the decentering of the anthropoid, through walking 
lawscapes, diagrammatic thinking, skillings not chillings in Rotterdam city, clinical environmental law pedagogies; and,

c. the all-pervasive potency of hyperchaos that drives this radical conception of spatiotemporality whereby the teaching of becoming and uncertainty allows us to understand our capacity to adapt as part of a greater ecological entanglement, and this system's power to adapt and prepare for the unnavigable at the same time.

To be speculative "is not about giving a plausible account of what exists but about approaching each society with the question of what it might be capable of, and this capacity designates not its judgments but the interstices to which it provides shelter" (Stengers 2011, 509). It is hoped this underpinning of complex processes to all performances, including environmental law pedagogy as exemplified through the paradigm-shifting projects of Skill City and lawscaping, has authenticated Stengers' definition of speculative thinking, with hope, responsibility and new horizons for us, our planet and the laws we create, at the very heart of this entropic journey into infinite possibilities unravelling in the new materialisms.

\section{References}

Agamben, Giorgio (2004), "The Open: Man and Animal", Stanford, Stanford University Press.

Aretoulakis, Emmanouil (2014), Towards a PostHumanist Ecology, European, 18, Journal of English Studies, 2, 172-190.

Arnheim, Rudolf (1971), Entropy and art: An essay on order and disorder, Berkeley: University of California Press.

Arnheim, Rudolf. 1973. On entropy and art, Leonardo 6(2): 188-189.

Aretoulakis, Emmanouil (2014), "Towards a PostHumanist Ecology", European Journal of English Studies, 18:2, 172-190.

Bergson, Henri (2014 [1907]), “Creative Evolution”, CreateSpace Independent Publishing Platform.

Bibel, Wolfgang. 2004. Al and the Conquest of Complexity in Law, 12, Artificial Intelligence and Law, 159-180.

Bloch, Ernst (1995), The Principle of Hope, Cambridge, Massachusetts, MIT Press.

Bottomley, Anne and Lim, H., eds. 2009. Feminist Perspectives on Land Law, Feminist Perspectives, Cavendish/Routledge, London.

Bottomley, Anne and Moore, Nathan (2008), "Blind Stuttering: Diagrammatic City", 17, Griffith Law Review, 2, 559-576.

Brillouin, Léon. (1953), Negentropy Principle of Information, 24, J. of Applied Physics, v. 9, $1152-$ 1163.

Bryant, Levi, Srnicek, Nick and Harman, Graham (eds.), "The speculative turn: Continental Materialism and Realism”, Melbourne, Re-Press.

Byrne, David (2005). 'Complexity, Configurations and Cases', Theory, Culture \& Society 22, no. 5, 95-111.

Castree, Noel and Nash, Cathryn (2004), 'Mapping posthumanism: an exchange', Environment and Planning A, volume 36, pages $1341-1363$.

Cilliers, Paul. What Is Complexity Science? A View from Different Directions, 3, Emergence, 3, 2001, $5-23$.

Cilliers, Paul. Complexity, Ethics and Justice, 5, Journal for Humanistics (Oct. 2004), p. $19-26$ (Amsterdam: Uitgeverij SWP).

Cilliers, Paul. 2005. Complexity, Deconstruction and Relativism. 22, Theory, Culture \& Society, 5, 255-267. 
Cudworth, Erika and Hobden, Stephen (2011), Posthuman International Relations: Complexity, Ecologism and Global Politics, London and New York: Zed Books.

Deleuze, Gilles and Guattari, Felix (2004), "A Thousand Plateaus: Capitalism and Schizophrenia", London: Continuum

Edelmann, Florian (2012), Complex Social System Thinking beyond Posthumanism: The Exclusion of Subjectivity and Possibilities for Human Agency, Millennium Annual Conference: Materialism and World Politics, LSE, 20-22 October 2012.

Elichirigoity F, (2000), "On failing to reach escape velocity beyond modernity" 30, Social Studies of Science, 145-150.

Emmett, Robert (2011), "Community Gardens, Ghetto Pastoral, and Environmental Justice", 18, Interdisciplinary Studies in Literature and Environment, 1, 67-86.

Escobar, Arturo. 2003. Other worlds are (already possible): Self-organisation, complexity, and post-capitalist cultures, in Sen, Jai, Anita Anand, Arturo Escobar, Peter Waterman, eds. (2005), The world social forum: Challenging empires, New Dehli: Viveka Foundation.

de Almeida Silva, Tagore Trajano (2014), "Origins and Development of Teaching Animal Law in Brazil", 31 Pace Envtl. L. Rev. 501.

DeHaan, Freek (2014), "Assessing Singularity Through Speculative Sociology: The Case of Rotterdam Skillcity", 1, O-Zone: A Journal of Object-Oriented Studies, 97-103.

de Landa, M. (2000), "A Thousand Years of Nonlinear History", New York: Swerve Editions.

de Landa, M. (2011), Emergence, Causality and Realism in Levi Bryant, Nick Srnicek and Graham Harman (eds.), "The speculative turn: Continental Materialism and Realism", Melbourne, Re-Press.

Houston, Donna (2008), "Crisis and resilience: Cultural methodologies for environmental sustainability and justice", 22, Continuum: Journal of Media \& Cultural Studies, 2, 179-190.

de Sousa Santos, Bouventura. 1995. Towards a New Common Sense: Law, Science and Politics in the Paradigmatic Transition, New York, Routledge.

de Sousa Santos, Bouventura. 1998. Oppositional Postmodernism and Globalisations, 23 Law and Social Inquiry, 1, 126.

de Sousa Santos, Boaventura. 1999. The fall of Angelus Novus: Beyond the modern game of roots and options, at www.eurozine.com.

de Sousa Santos, Bouventura. 2001. Nuestra America, Reinventing a Subaltern Paradigm of Recognition and Redistribution, 18, Theory, Culture and Society, 2-3, 185-217.

de Sousa Santos, Bouventura. 2003. The World Social Forum: Toward a Counter-Hegemonic Globalisation, in Sen, Jai, Anand, Anita, Escobar, Arturo, and Waterman, Pete (Eds.) (2004), World Social Forum: Challenging Empires, New Delhi, The Viveka Foundation.

de Sousa Santos, Boaventura. 2004. A critique of lazy reason: Against the waste of experience, in Wallerstein, Immanuel. ed., The modern world-system in the Long Durée, Colorado: Boulder.

de Sousa Santos, Boaventura and César Rodríguez-Garavito, eds. 2005. Law and globalization from Below: Towards a cosmopolitan legality, Cambridge: Cambridge Studies in Law and Society.

Dryzek, S. (2012) The politics of the Earth: Environmental discourses (3rd edn), Oxford, Oxford University Press.

Farber, Daniel (2006), "Probabilities Behaving Badly: Complexity Theory and Environmental Uncertainty", Davis University, Vol 37, 145.

Feenberg A, (2000), "Will the real post-human please stand up", 30, Social Studies of Science, 151157.

Gavin, Rae (2014), 'Heidegger's influence on posthumanism: The destruction of metaphysics, technology and the overcoming of anthropocentrism', 27, History of the Human Sciences, 1, 51-69. 
Griffioen, Aetzel (2015), "Short Remarks on an Ecosophical Pedagogy", Le Merle. Vol. 3, no.1, Montreal, $59-68$.

Guattari, Felix (1989), "The Three Ecologies", London and New York, Continuum.

Guattari, Félix (1995), "Chaosmosis: An ethico-aesthetic paradigm", Bloomington, Indianapolis: Indiana University Press.

Hägglund, Martin (2011), "Radical Atheist Materialism: A Critique of Meillassoux" in Levi Bryant, Nick Srnicek and Graham Harman (eds.), "The speculative turn: Continental Materialism and Realism", Melbourne, Re-Press.

Hallward, Peter (2011), 'Anything is Possible: A Reading of Quentin Meillassoux's After Finitude' in Levi Bryant, Nick Srnicek and Graham Harman (eds.), "The speculative turn: Continental Materialism and Realism", Melbourne, Re-Press.

Harris, Graham (2007), "Seeking Sustainability in an age of Complexity" Cambridge, Cambridge University.

Johnson, Stephen. 2001. Emergence, New York, Scribner.

Kavalski, Emilian (2007), 'The Fifth Debate and the Emergence of Complex International Relations Theory: Notes on the Application of Complexity Theory to the Study of International Life', Cambridge Review of International Affairs 20, no. 3: 435-454.

Ko, Sebastian (2013), 'Legal Treatment of Complexity: the Unwieldiness of Environmental Law', 1 Environmental Liability, 25-28.

Latour, Bruno (2007), "Reassembling the Social: An Introduction to Actor-Network-Theory", London, Clarendon.

Law, John (2004), "After method: Mess in social science research", Abingdon, Routledge.

Luhmann, Niklas (2012) "An Introduction Systems Theory", London: Polity Press.

Meillassoux, Quentin (2008), "After Finitude: An Essay on the Necessity of Contingency", London, Continuum.

Milovanovic, Dragan. 1992. Postmodern law \& disorder: Psychoanalytical semiotics, chaos \& juridical exegesis. Liverpool: Deborah Charles.

Milovanovic, Dragan. 1997. Chaos, criminology \& social justice: The new dis(order). London:

Greenwood Press.

Norde, William (1997), Energy and entropy: a thermodynamic approach to sustainability, 17, 1, 57-62

Nowotny, Helga (2005), 'The Increase of Complexity and its Reduction: Emergent Interfaces between the Natural Sciences, Humanities and Social Sciences', Theory, Culture \& Society 22, no. 5: 15-31.

Ó Maoilearca, John (2014), "Spirit In The Materialist World", 19, Angelaki: Journal of the Theoretical Humanities, 1, 13-29.

Philippopoulos-Mihalopoulos, Andreas (2011) (Ed.), "Law and Ecology: New Environmental Foundations", London, Routledge.

Philippopoulos-Mihalopoulos, Andreas (2015), "Spatial Justice: Body, Lawscape, Atmosphere", Space Materiality and the Normative Series, London, Routledge.

Rae, Gavin (2014), 'Heidegger's influence on posthumanism: The destruction of metaphysics, technology and the overcoming of anthropocentrism', 27, History of the Human Sciences, 1, 51-69 Ramey, Joshua (2014), "Contingency Without Unreason", 19, Angelaki: Journal of the Theoretical Humanities, $1,31-46$. 
Ruhl, J.B. 1996a. Complexity theory as a paradigm for the dynamical law-and-society system: A wake-up call for legal reductionism and the modern administrative state, Duke Law Journal 45(5): 849-927.

Ruhl, J.B. 1996b. The Fitness of Law: Using Complexity Theory to Describe the Evolution of Law and Society and Its Practical Meaning for Democracy.

Ruhl, J.B. 1997. The Arrow of Law in Modern Administrative States: Using Complexity Theory to Reveal the Diminishing Returns and Increasing Risks the Burgeoning of Law Poses to Society.

Schrödinger, Erwin. (1944), What is Life?, Cambridge: Cambridge University Press.

Stengers, Isabel (2011), "Thinking with Whitehead" Cambridge, MA: Harvard University Press.

Stone, Christopher (2010), "Should Trees Have Standing? Law, Morality and the Environment", Oxford, Oxford University Press.

Urry, John (2005). 'The Complexity Turn', Theory, Culture \& Society 22, no. 5, 1-14, 1.

Urry, John (2006). 'Complexity', Theory, Culture \& Society 23, no. 2-3, 111-115.

Webb, Julian. 2004-2005. Law, Ethics, and Complexity: Complexity Theory \& The Normative Reconstruction Of Law. 52 Clev. St. L. Rev. 227 2004-2005.

Webb, Thomas. 2013. Exploring system boundaries. Law and Critique, 24(2), 131-151.

Whatmore S, (2002), "Hybrid Geographies: Natures Cultures Spaces", London: Sage.

Williams, Alex and Srnicek, Nick (2014), "\#ACCELERATE MANIFESTO for an Accelerationist Politics" found at https://syntheticedifice.wordpress.com/2014/03/13/accelerate-manifesto-for-anaccelerationist-politics/, accessed 19 July 2015.

Žižek, Slavoj (2006), The Parallax View, Cambridge, The MIT Press.

\section{Appendices}

\section{Appendix 1 - Skill City}

\section{Appendix 2- Walking the Lawscape (Andreas Phillippopoulos-Mihalopoulos, 2015: 96)}

"Walking observing thinking acting breaking flowing going against listening taking notes mapping smelling touching do not touch forgetting remembering overhearing running escaping getting lost feeling lost fearing deviating diverting avoiding throwing yourself in manipulating never stopping moving being moved

\section{Walking the lawscape}

Take a long walk, about 45 minutes or so, preferably alone. Try to map where you are going but without worrying too much about accuracy. Do not only take the main streets or the streets you already know. Take side streets, get tangled in places you do not know, feel a little lost (but always keep safe, use your instinct and reason to keep out of trouble, and carry with you a map so you do not actually get lost).

\section{While walking}

Keep in mind three things: yourself, your movement, your surroundings. Try to analyse the connection between all three:

1. Does your body move differently in different aituations?

2. Do you think of different things depending on where you are? 
3. Do you feel constrained in your movement by anything internal (you) or external (the city)?

Think also of the way you use your senses while walking:

1. Do you smell?

2. Do you touch?

3. Do you ever look upwards?

4. Do you notice what other people say to each other or on their phones?

5. Can you eat/smoke/chew gum and walk? Does it bother you?

\section{The assemblage}

Now if you have an assemblage of your body/the city/the law. See whether all of it moves as one, whether you map the cit you are creating, and/or whether the city determines your movement, and to what extent the law determines you and the city.

See how this assemblage deals with:

1. The law: where is the law in the city? Do you see it determining where you can walk and where not? How you walk? When you walk and when you stop? What sitances do you keep from things/people? What senses can you use?

2. The body as hybrid: can you see any hybrids anywhere? Human/animal/technological hybrids? Are you a hybrid? Do you use your sense in an 'animal' way- e.g., does smell stop you from doing things?

3. Space: what is space? What is urban space? Can you differentiate space from body - the city space you are walking and creating from your body? Is your body part of the space? Is law spatial? 